\title{
Self-Regulation, Motivation, and Psychosocial Factors in Weight Management
}

\author{
Pedro J. Teixeira, ${ }^{1}$ Jutta Mata, ${ }^{2}$ Geoffrey C. Williams, ${ }^{3}$ \\ Amy A. Gorin, ${ }^{4}$ and Simone Lemieux ${ }^{5}$ \\ ${ }^{1}$ Department of Exercise and Health, Faculty of Human Kinetics, Technical University of Lisbon, 1495-688 Cruz Quebrada, Portugal \\ ${ }^{2}$ Adaptive Rationality Center, Max Planck Institute for Human Development, Lentzeallee 94, 14195 Berlin, Germany \\ ${ }^{3}$ Department of Medicine, Center for Community Health, University of Rochester, Rochester, NY 14607, USA \\ ${ }^{4}$ Department of Psychology, Center for Health, Intervention, and Prevention, University of Connecticut, 406 Babbidge Road, Unit 1020, \\ Storrs, CT 06269-1020, USA \\ ${ }^{5}$ Institute of Nutraceuticals and Functional Foods (INAF), Laval University, Québec, Canada G1V0A6
}

Correspondence should be addressed to Pedro J. Teixeira, pteixeira@fmh.utl.pt

Received 15 October 2012; Accepted 15 October 2012

Copyright (C) 2012 Pedro J. Teixeira et al. This is an open access article distributed under the Creative Commons Attribution License, which permits unrestricted use, distribution, and reproduction in any medium, provided the original work is properly cited.

Any attempt to self-regulate one's body weight takes place at the intersection of the external environment and innate biological predispositions that, especially when combined, can be highly conducive to energy surpluses and excessive fat mass accretion. Prominent examples of such factors are high availability of calorie dense, palatable foods, economical constraints that negatively influence lifestyle choices, and the human predisposition for liking sweet and fatty foods. As a consequence, it is no surprise that the majority of individuals have become overweight or obese, apparently "losing control" and "succumbing" to these external and internal obesogenic pressures. At the same time, it is known that behaviors related to body weight regulation, namely, physical activity and diet, are generally within the reach of voluntary control and regulation, as evidenced by studies of successful weight loss maintainers who report dramatic changes in their lifestyles despite being surrounded by seemingly obesogenic environments [1]. These improvements have frequently been linked to individuals finding new ways of relating to one's weight and lifestyle, new selfperceptions, motives, goals, emotional responses, habits, and so forth (e.g., [2-4]). This apparent paradox is reinforced by a frequent tension between population-level ("environmental," "political") versus individual-level ("motivational," "self-regulatory") approaches to addressing the problem of obesity, which may be misguided; both will likely be necessary and one can inform the other.

Various perspectives can be taken to address obesity prevention and treatment. One is that obesity, at a population level, is largely "caused" by environmental factors and consequently it should primarily be tackled with public health measures [5]. Other views, informed by advances in molecular biology, tend to favor approaches rooted in the genetics of obesity (e.g., prevention by early risk diagnosis) [6] and/or pharmacological solutions to treat the most prevalent forms of obesity [7]. Lately, interventions derived from applying principles of behavioral economics have come forth with solutions based on "nudges" and small changes in contextual "default conditions," as they bypass individuals' volition, biases, and errors in judgment [8]. While other perspectives exist (e.g., $[9,10]$ ), this special issue is a statement that exploring psychological determinants of health behavior such as reasons, goals, expectations, values, beliefs, or selfperceptions - and getting individuals more (and better) motivated in self-managing their health, remain important aspects to address in fighting obesity. While, in concept, no one disputes that motivational factors or, more generally, psychosocial processes are relevant to understanding why people behave the way they do, in regards to their health, this topic has sometimes been presented as "old news" in 
obesity research, which is premature. We believe that a more productive stance is one that recognizes that a multitude of perspectives and solutions must be effectively integrated in order to more successfully fight obesity [11].

Environmental change may be slow to implement, can be very expensive, is often stalled by industries with competing interests, and can have unpredictable and even paradoxical outcomes, all of which makes research in this area a formidable challenge [12]. Furthermore, social and economical conditions will evolve, and many people will move across different physical and cultural environments through the course of their lives (sometimes for long periods), which could limit the efficacy of some environmental interventions. Therefore, it is crucial to also improve existing strategies and develop new strategies that help people better navigate obesogenic environments, wherever and whenever they exist, by maximizing their own self-regulatory resources. Again, a critical point is that population-based initiatives to fight obesity can and should be informed by "individuallevel" research (e.g., mass, internet-based campaigns to promote fruits and vegetables which apply sound theorybased motivational principles); similarly, "individual-level" interventions (e.g., primary care consultations) should be mindful of research findings in areas such as the impact of the built environment of physical activity or how contextual "nudges" impact health-related decisions and behavior. Regardless, all these initiatives must be supported by focused, high-quality research that seeks to understand why, how, and under which conditions children, adolescents, and adults are more likely to remain at, or achieve healthful levels of body weight. This special issue aims to make a contribution to this research.

The 14 articles published in this special issue underline the importance of psychological factors in the context of body weight self-regulation. For instance, L. Karhunen and colleagues [13] show that psychobehavioral factors are more important for weight regulation than individual satiety levels or diet characteristics, whereas E. A. Dennis and colleagues [14] point out the difficulty of maintaining weight during freshman year at college, even with explicit training in self-regulation skills. C. Bégin and colleagues [15] demonstrate that self-regulation during weight loss attempts systematically differs between women with lower and higher depressive symptoms, underlining the importance of psychological health and wellbeing as a prerequisite in selfregulation of health behaviors.

Three articles investigate the role of self-perceived weight in adolescents. R. C. Krauss and colleagues [16] show that accuracy differences in weight perceptions explain some of the weight disparities between adolescents of different ethnic groups in the US. K. Ojala and colleagues [17] report that overweight boys and girls in Finland accurately perceived their weight as higher and had a lower body image than normal-weight children. Importantly, adolescents who perceived themselves as being overweight despite being in a healthy weight range were more likely to actually be overweight 11 years later [18].

Three articles examine physical activity, a health behavior central in weight management. E. Guérin and M. S. Fortier
[19] showed how situational motivation and perceived exercise intensity predict changes in positive affect following physical activity. D. S. Buchan and colleagues [20] reviewed current psychological models for increasing physical activity levels and describe the need for more ecological models. M. L. Segar and colleagues [21] show that framing physical activity as a way to positively influence daily well-being enhanced body image and perceptions about the physical activity experience in overweight women.

Three articles investigate the role of the social environment for self-regulation of bodyweight, particularly, the role of parents in children's and adolescents' weight management. K. P. Jakubowski and colleagues [22] showed that parental readiness to change weight control behaviors was predictive of adolescents' body mass index at treatment end. In their review, L. A. Frankel and S. O. Hughes [23] made interesting connections, applying the literature on parental influence on their children's emotion regulation to parental influence on self-regulation of energy intake in children. These articles point to the importance of the interaction of the social environment (parents) with the self-regulation of weightrelated behaviors in children and adolescents. S. B. Gesell and colleagues [24] report on a different aspect of the parent-child relation in the context of weight management. They show that over the course of a three-month obesity prevention trial parents form new social ties with parents of children with similar body types. Thus, parents of obese children were more likely to become friends with parents of other obese children and parents of normal-weight children would befriend parents of other normal-weight children more often.

Another central topic in self-regulation is an individual's motivation. Two articles examined the role of external motivation, namely, monetary incentives for weight regulation. M. M. Crane and colleagues [25] showed somewhat surprisingly that small monetary incentives did not influence autonomous or controlled motivation for participation in a 1-year weight loss trial. In contrast, the findings by A. C. Moller and colleagues [26] demonstrate that participants in a three-week health behavior improvement program who reported being more motivated by a monetary incentive had higher body weight at 17 weeks followup. Finally, J. Y. Breland and colleagues [27] suggest the Common-Sense Model of Self-Regulation as a framework for organizing existent tools and creating new means to improve long-term weight regulation.

We believe this special Issue will enhance our understanding of psychological—especially motivational and selfregulatory-factors in weight management and, collectively, provide an interesting snapshot of research in this area, with a good share of innovative empirical findings (e.g., $[18,23$, 26]) and fresh conceptual discussions (e.g., [20, 23, 27]).

As a final note, it is important to remember, especially when dealing with issues involving individual selfregulation, that our society protects human freedom of choice. Biomedical ethics, the legal system in the US, and medical professionalism protect patient autonomy in health care and in research studies and have recently agreed that it should be a primary outcome of all health care interactions 
([28-31]). The need to respect patient autonomy in all health care interventions is mandated and thus is not a choice for whether practitioners, policy makers, or researchers will support it in a particular intervention. Thus, more research is needed to understand how autonomous self-regulation is affected by public health messaging, clinical and community programs, food industry advertising, economic rewards and punishments, and genetics. Also, health care is delivered in a free choice paradigm; thus, interventions must focus on helping participants to choose options that help them maintain their weight or weight loss and which they want to continue to choose after the intervention's end. To determine the success of an intervention, researchers are strongly encouraged to document the effect of their interventions for a period of at least 6 months after the intervention ends. For obesity, known for its high recidivism, this period might be even longer.

\section{Pedro J. Teixeira Jutta Mata Geoffrey C. Williams Amy A. Gorin Simone Lemieux}

\section{References}

[1] S. Phelan, T. Liu, A. Gorin et al., "What distinguishes weightloss maintainers from the treatment-seeking obese? Analysis of environmental, behavioral, and psychosocial variables in diverse populations," Annals of Behavioral Medicine, vol. 38, no. 2, pp. 94-104, 2009.

[2] P. T. Fuglestad, R. W. Jeffery, and N. E. Sherwood, "Lifestyle patterns associated with diet, physical activity, body mass index and amount of recent weight loss in a sample of successful weight losers," The International Journal of Behavioral Nutrition and Physical Activity, vol. 9, no. 1, p. 79, 2012.

[3] M. L. Butryn, S. Phelan, J. O. Hill, and R. R. Wing, "Consistent self-monitoring of weight: a key component of successful weight loss maintenance," Obesity, vol. 15, no. 12, pp. 30913096, 2007.

[4] M. N. Silva, D. Markland, E. V. CarraÇa et al., "Exercise autonomous motivation predicts 3-yr weight loss in women," Medicine and Science in Sports and Exercise, vol. 43, no. 4, pp. 728-737, 2011.

[5] A. N. Gearhardt, M. A. Bragg, R. L. Pearl, N. A. Schvey, C. A. Roberto, and K. D. Brownell, "Obesity and public policy," Annual Review of Clinical Psychology, vol. 8, pp. 405-430, 2012.

[6] R. J. Loos, "Genetic determinants of common obesity and their value in prediction," Best Practice \& Research: Clinical Endocrinology \& Metabolism, vol. 26, no. 2, pp. 211-226, 2012.

[7] F. Cameron, G. Whiteside, and K. Mckeage, "Phentermine and topiramate extended release (qsymia): first global approval," Drugs, vol. 72, no. 15, pp. 2033-2042, 2012.

[8] D. R. Just and C. R. Payne, "Obesity: can behavioral economics help?” Annals of Behavioral Medicine, vol. 38, supplement 1, pp. S47-S55, 2009.

[9] S. W. Keith, D. T. Redden, P. T. Katzmarzyk et al., "Putative contributors to the secular increase in obesity: exploring the roads less traveled," International Journal of Obesity, vol. 30, no. 11, pp. 1585-1594, 2006.

[10] D. De Ridder, "Themed issue: plans, norms, motivation, and cheating a little-the curious case of healthy eating," Psychology \& Health, vol. 27, supplement 2, pp. 1-6, 2012.
[11] J. Lakerveld, J. Brug, S. Bot et al., "Sustainable prevention of obesity through integrated strategies: the SPOTLIGHT project's conceptual framework and design," BMC Public Health, vol. 12, no. 1, p. 793, 2012.

[12] J. L. Pomeranz and K. D. Brownell, "Portion sizes and beyond-government's legal authority to regulate foodindustry practices," The New England Journal of Medicine, vol. 367, pp. 1383-1385, 2012.

[13] L. Karhunen, M. Lyly, A. Lapvetelainen et al., "Psychobehavioural factors are more strongly associated with successful weight management than predetermined satiety effect or other characteristics of diet," Journal of Obesity, vol. 2012, Article ID 274068, 14 pages, 2012.

[14] E. A. Dennis, K. L. Potter, P. A. Estabrooks, and B. M. Davy, "Weight gain prevention for college freshmen: comparing two social cognitive theory-based interventions with and without explicit self-regulation training," Journal of Obesity, vol. 2012, Article ID 803769, 10 pages, 2012.

[15] C. Bégin, S. De Grandpre, and M. P. Gagnon-Girouard, "Eating and psychological profiles of women with higher depressive symptoms who are trying to lose weight," Journal of Obesity, vol. 2012, Article ID 846401, 10 pages, 2012.

[16] R. C. Krauss, L. M. Powell, and R.. Wada, "Weight misperceptions and racial and ethnic disparities in adolescent female body mass index," Journal of Obesity, vol. 2012, Article ID 205393, 9 pages, 2012.

[17] K. Ojala, J. Tynjala, R. Valimaa, J. Villberg, and L. Kannas, "Overweight adolescents' self-perceived weight and weight control behaviour: HBSC study in Finland 1994-2010," Journal of Obesity, vol. 2012, Article ID 180176, 9 pages, 2012.

[18] K. Cuypers, K. Kvaloy, G. Bratberg, K. Midthjell, J. Holmen, and T.L. Holmen, "Being normal weight but feeling overweight in adolescence may affect weight development into young adulthood-an 11-year followup: the HUNT study, Norway," Journal of Obesity, vol. 2012, Article ID 601872, 8 pages, 2012.

[19] E. Guérin and M. S. Fortier, "Situational motivation and perceived intensity: their interaction in predicting changes in positive affect from physical activity," Journal of Obesity, vol. 2012, Article ID 269320, 7 pages, 2012.

[20] D. S. Buchan, S. Ollis, N. E. Thomas, and J. S. Baker, "Physical activity behaviour: an overview of current and emergent theoretical practices," Journal of Obesity, vol. 2012, Article ID 546459, 11 pages, 2012.

[21] M. L. Segar, J. A. Updegraff, B. J. Zikmund-Fisher, and C. R. Richardson, "Physical activity advertisements that feature daily well-being improve autonomy and body image in overweight women but not men," Journal of Obesity, vol. 2012, Article ID 354721, 2012.

[22] K. P. Jakubowski, J. J. Black, N. E. El Nokali et al., "Parents' readiness to change affects BMI reduction outcomes in adolescents with polycystic ovary syndrome," Journal of Obesity, vol. 2012, Article ID 298067, 12 pages, 2012.

[23] L. A. Frankel and S. O. Hughes, "Parental influences on Children's self-regulation of energy intake: insights from developmental literature on emotion regulation," Journal of Obesity, vol. 2012, Article ID 327259, 12 pages, 2012.

[24] S. B. Gesell, K. D. Bess, and S. L. Barkin, "Understanding the social networks that Form within the context of an obesity prevention intervention," Journal of Obesity, vol. 2012, Article ID 749832, 10 pages, 2012.

[25] M. M. Crane, D. F. Tate, E. A. Finkelstein, and L. A. Linnan, "Motivation for participating in a weight loss program and financial incentives: an analysis from a randomized trial," Journal of Obesity, vol. 2012, Article ID 290589, 9 pages, 2012. 
[26] A. C. Moller, H. G. Mcfadden, D. Hedeker, and B. Spring, "Financial motivation undermines maintenance in an intensive diet and activity intervention," Journal of Obesity, vol. 2012, Article ID 740519, 8 pages, 2012.

[27] J. Y. Breland, A. M. Fox, C. R. Horowitz, and H. Leventhal, "Applying a common-sense approach to fighting obesity," Journal of Obesity, vol. 2012, Article ID 710427, 8 pages, 2012.

[28] American Society of Internal Medicine and European Federation of Internal Medicine, "Medical professionalism in the new millennium: a physician charter," Annals of Internal Medicine, vol. 136, no. 3, pp. 243-246, 2002.

[29] T. L. Beauchamp and J. F. Childress, Principles of Biomedical Ethics, Oxford University Press, New York, NY, USA, 6th edition, 2009.

[30] Omnibus Budget Reconciliation Act of 1990., in Public Law 101-508 42964751 (codified in scattered sections of 42 USC), 1990.

[31] S. H. Woolf, E. C. Y. Chan, R. Harris et al., "Promoting informed choice: transforming health care to dispense knowledge for decision making," Annals of Internal Medicine, vol. 143, no. 4, pp. 293-300, 2005. 


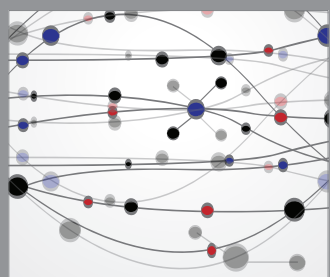

The Scientific World Journal
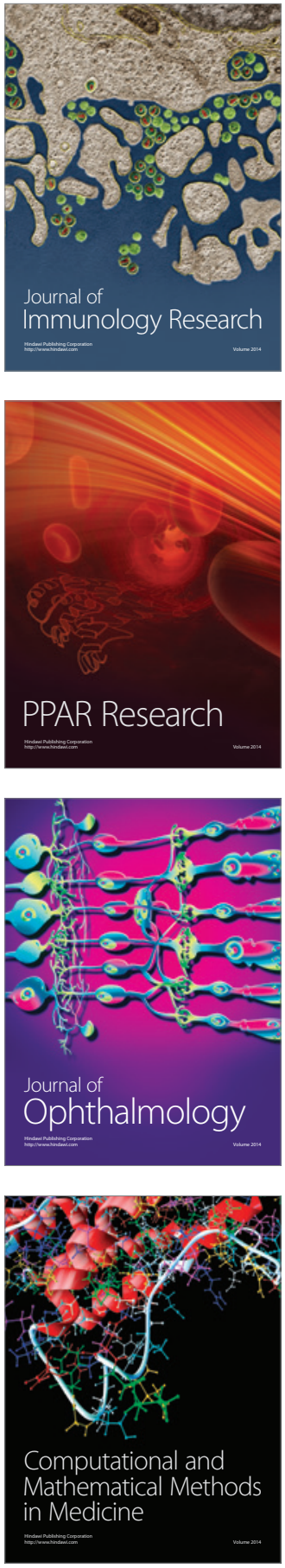

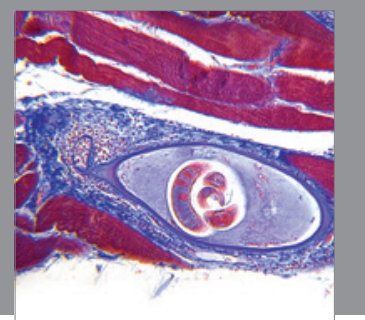

Gastroenterology

Research and Practice
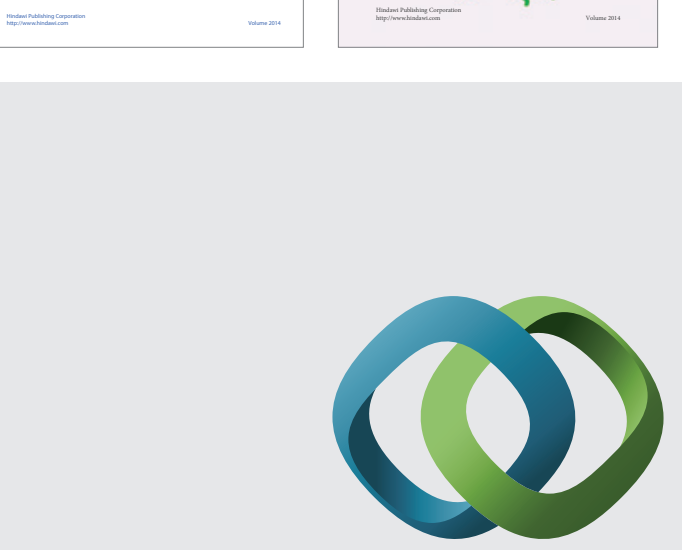

\section{Hindawi}

Submit your manuscripts at

http://www.hindawi.com
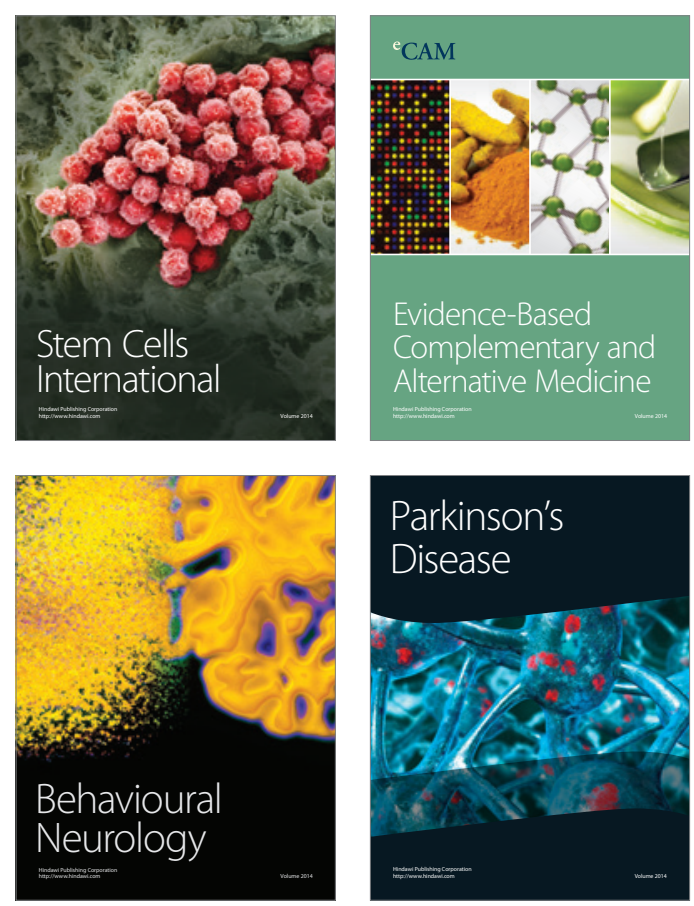

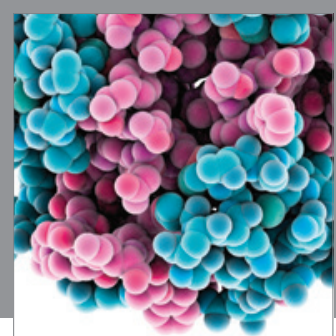

Journal of
Diabetes Research

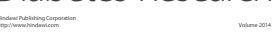

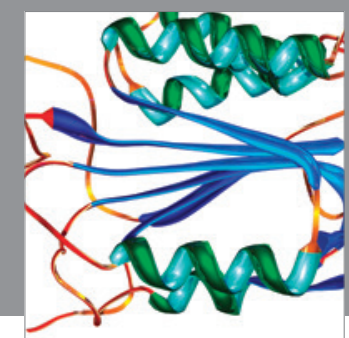

Disease Markers
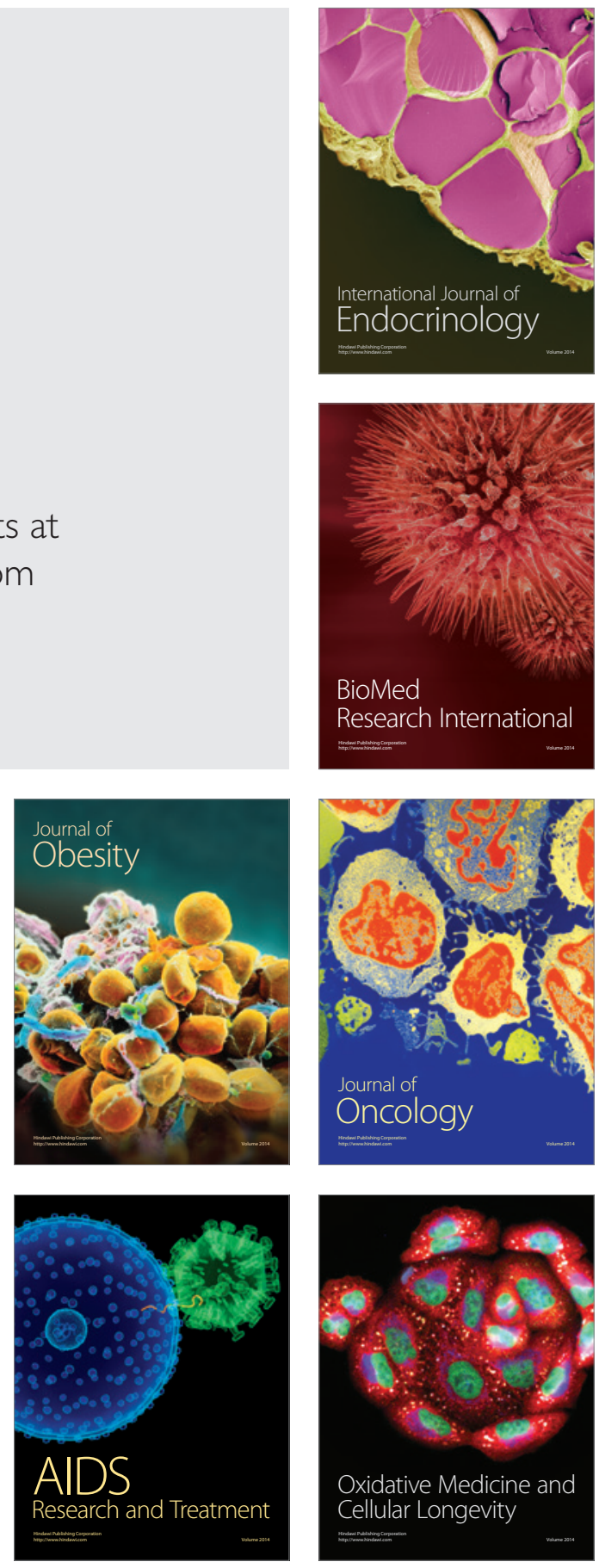